\title{
Aldosterone and Parathyroid Hormone: Evidence for a Clinically Relevant Relationship
}

\author{
Vismay Naik* \\ PG Diploma in Endocrinology and Diabetes, Ashirvad Heart and Diabetes Centre, India
}

Submission: April 13, 2019; Published: May 06, 2019

*Corresponding author: Vismay Naik, MD, MRCP(UK), PG Diploma in Endocrinology and Diabetes, Ashirvad Heart and Diabetes Centre, India

\section{Introduction}

A 'new endocrine axis', involving the bi-directional relationship between the parathyroid hormone (PTH) and the reninangiotensin-aldosterone system (RAAS) has been established recently. Individually these have long been recognized, although it is only in recent times that we are realizing the interplay between the two and the corresponding effects this has on the physiological and pathological roles within the body. Other calciotropic hormones such as Vitamin D are also impacting on this relationship [1]. This report aims to highlight the cyclic nature of these relationships, through the physiological pathways, which will then lead into pathological disease in multiple areas such as heart failure, cardiovascular health and bone homeostasis. It is through this it is hoped to highlight this new bi-directional relationship.

Physiological effects of Calcitrophic Hormones on the RAAS

PTH is thought to influence aldosterone secretion in the zona glomerulosa of the adrenal glands [2]. This was demonstrated by Mazzocchi et al. [3], who found that PTH exerts a significant stimulatory action on aldosterone secretion by adrenocortical cells, through the PTH/PTH-RP receptors. PTH is also thought to directly stimulate renin release in the myoepithelial cells of the preglomerular arterioles [4]. Increased activity of the RAAS, and raised aldosterone levels, have been demonstrated in patients with primary hyperparathyroidism. Parathyroidectomy, and its associated reduction in PTH, has been shown to result in normalization of the RAAS system and aldosterone levels.

Physiological Effects of RAAS on the Calciotrophic Hormones and Calcium Homoestasis

Recent observational studies in individuals with primary hyperaldosteronism suggest that excess aldosterone may result in hyperparathyroidism. A better understanding of the normal physiologic relationship between the RAAS and PTH is of clinical relevance since inappropriate activity of both PTH and the RAAS may negatively impact cardiovascular and skeletal health [5]. Hyperaldosteronism is associated with a reversible secondary hyperparathyroidism due to increased renal and faecal calcium excretion. PTH is increased as a result of the MR (mineralocorticoid receptor) mediated calciuretic and magnesiuretic effects, with a trend towards hypocalcemia, hypomagnesemia and the direct effects of aldosterone on parathyroid cells via binding to the MR. Moreover, the angiotensin II receptor is expressed by human parathyroid tissue, and angiotensin may therefore directly stimulate PTH secretion [6].

\section{RAAS and Vitamin D}

Aldosterone acts through the mineralocorticoid receptor, which belongs to the same superfamily of nuclear receptors as the vitamin D receptors (VDR). Therefore, cross talk between these receptors and their agonists could potentially exist. [7]. Vitamin D has been shown to have an inverse relationship with renin levels [8]. Tomaschitz et al. [9] demonstrated that vitamin D deficient patients had significantly higher levels of renin, angiotensin 2 and aldosterone. In a subsequent study, Vaidya et al. [10] found that higher levels of Vitamin D were associated with lower plasma renin activity under both salt conditions, supporting the hypothesis that vitamin D acts as an inhibitor of renin production.

\section{Bi-directional interplay between PTH and RAAS in Different Systemic Diseases}

Neurohormonal activation is a hallmark of chronic heart failure (HF). Low perfusion pressure due to impaired left ventricular function results in the activation of the sympathetic nervous system and the RAAS. Stimulation of adrenal aldosterone synthesis in chronic HF occurs despite sodium and fluid retention. The hyperadrenergic state leads to translocation of cations into the intracellular compartment and the increased aldosterone secretion stimulates faecal and urinary loss of cations. The resulting hypocalcemia and hypomagnesaemia stimulate PTH secretion which tends to restore extracellular calcium and magnesium homeostasis. The PTH promotes mitochondrial $\mathrm{Ca} 2+$ excess in the myocardium which leads to oxidative stress and necrotic cell death which, in the long term, 
causes or amplifies myocardial fibrosis thus aggravating systolic and diastolic HF [11].

PTH also directly stimulates aldosterone synthesis by binding to the PTH/PTH-rP receptor, voltage-gated calcium channels, and the adrenocorticotropic hormone receptor, thus triggering a vicious cycle of mutually reinforcing aldosteronism and hyperparathyroidism. Relative aldosterone excess causes sodium retention and oxidative stress, thus increasing CV morbidity and mortality [2]. PTH also contributes to the development of arterial stiffness, arterial hypertension, and cardiac hypertrophy via binding to the PTH/PTH-rP receptor, which is expressed in vascular smooth muscle cells and cardiomyocytes. In addition, aldosterone excess exerts genomic (by binding to the MR), and non-genomic profibrotic and proinflammatory effects on blood vessels and the myocardium [12].

\section{Aldosterone-Parathyroid Hormone Interactions in Primary Hyperparathyroidism}

Early evidence for a physiological and pathophysiological bidirectional link between aldosterone and PTH in humans had initially been derived mainly from casereports. Subsequentstudies documented the presence of secondary-hyperaldosteronism in patients with primary-hyperparathyroidism, subsequently a marked reduction in plasma-aldosterone, angiotensin II and renin-activity was noted after parathyroidectomy [13]. Thus, in patients with hyperparathyroidism, the concomitant hyperaldosteronism can aggravate arterial-stiffness, endothelialdysfunction, blood pressure-elevation, vascular-remodelling, cardiac hypertrophy/failure and CVD.

Several studies revealed that patients with PA have alterations in calcium and increased PTH levels [14]. Treatment of PA with either MR-antagonist or adrenalectomy was found to decrease PTH levels [15]. PTH levels were significantly higher in aldosterone-producing adenomas compared to bilateral adrenal-hyperplasia, suggesting that the severity of aldosteronism correlated with severity of hyperparathyroidism. The concomitant hyperparathyroidism could contribute to skeletal diseases and compound CV-risk (beyond the CV-risk associated with PA) [2].

\section{Aldosterone-Parathyroid Hormone Interactions in Bone Diseases}

In addition to reversible elevation in PTH levels, reversible PTH mediated bone loss as evidenced by reduction in bonemineral density (BMD), osteoporosis and vertebral fractures were reported in patients with PA. Studies have demonstrated that surgery or medical treatment of PA reduced PTH levels and increased BMD on follow up. Though, bone loss is mostly mediated by PTH, additional mechanisms have been proposed, including a direct effect of aldosterone on bone (MR-expression has been identified in osteoblasts and osteoclasts). Spironolactone has been shown to lower fracture-risk in HF and RAAS-inhibitors lower PTH in CKD.

\section{Primary and Secondary Hyperaldosteronism}

Primary aldosteronism (PA) represents a major cause of secondary hypertension with high cardiovascular morbidity and mortality. Secondary hyperaldosteronism (SA) indicates a bidirectional functional link between the adrenal and parathyroid glands. PA patients have been shown to have a significant increase of primary hyperparathyroidism (PPTH) [16]. Conversely, undetected hyper-functioning of the parathyroid gland can contribute to maintaining PA [17].

Hyperaldosteronism and hyperparathyroidism represent pathophysiologic conditions that correlate with each other; aldosterone regulates parathyroid hormone causing adverse skeletal complications and PTH regulates aldosterone and associates with adverse cardiovascular complications [18]. PTH stimulates in vitro the secretion of aldosterone from human adrenocortical cells in a concentration dependent manner which suggests that PTH acts as an aldosterone secretagogue that may cause human PA [3].

High aldosterone levels are associated with high PTH levels $[14,19]$. Brunaud L et al [13], observed that elevated aldosterone levels, positively correlated with PTH levels in patients with primary hyperparathyroidism and PTH levels $>100 \mathrm{ng} / \mathrm{L}$ were an independent predictor of abnormally elevated plasma aldosterone concentration. So, primary hyperparathyroidism is associated with high aldosterone levels and primary aldosteronism is associated with high PTH levels. It is also suggested that PA contributes to secondary hyperparathyroidism [20].

Effect of Therapeutic Interventions on the Calciotrophic and Renin Angiotensin Aldosterone Systems

\section{Role of PTH surgery on Hyperaldosteronism and CVD Risk Factors}

Chronic heart failure, along with hypercalciuria, hypocalcaemia and secondary hyperparathyroidism with subsequent intracellular calcium overload is frequently found in patients with low-renin hypertension and primary aldosteronism. Interplay between the hormones regulating calcium homeostasis and the RAAS contribute to the pathogenesis of arterial hypertension. Brunaud et al. [13] reported significantly decreased aldosterone, angiotensin II, renin activity and blood pressure levels after parathyroidectomy with primary hyperparathyroidism.

\section{Effect of RAAS Blockage and Adrenalectomy on Hyper- parathyroidism and Vitamin D Levels}

Drugs affecting the RAAS and surgical treatment is associated with an increase in ionised calcium and a decrease in PTH (Rossi E). Adrenalectomy or MR blockers both decrease PTH secretion, arterial blood pressure as well as bone resorption. Animal studies show strong support for vitamin D3 mediated downregulation of 
renin expression and RAS activity via its interaction with vitamin D receptor [21]. Appendix 1 shows the influence untreated low Vitamin D levels can have on cardiovascular health, via the RAAS and PTH pathways [22-24].

\section{Conclusion}

As shown, increasing evidence is showing a bi-directional interplay between calciotrophic hormones, such as PTH, Vitamin $\mathrm{D}$ and the RAAS system. Calcitrophic hormones, particularly PTH and Vitamin D, have a cyclic nature on the RAAS system, affecting each at different receptor and cellular levels. As discussed, there are multiple pathways to consider. For example, the role of PTH's direct stimulatory action on aldosterone, or hyperaldosteronism's association with hyperparathyroidism. Or how Vitamin D shares the same receptor as aldosterone, and in vitamin D deficient patients the direct effect on the RAAS, through significantly higher levels of renin, angiotensin 2 and aldosterone. PTH and aldosterone both influence different pathological factors. As shown, it is this relationship between these calciotrophic hormones and the RAAS system that can adversely affect the disease states such as CVD, HF, PA \& SA. It is through the recognition of this new 'endocrine axis' that there is a clinically relevant relationship between these hormones. From this, surgical and therapeutic interventions can be tailored with this relationship in mind, to ensure optimum treatment outcomes.

\section{References}

1. Brown J, de Boer IH, Robinson-Cohen C, Siscovick DS, Kestenbaum B, et al. (2015) Aldosterone, parathyroid hormone, and the use of reninangiotensin-aldosterone system inhibitors: the multi-ethnic study of atherosclerosis. The Journal of Clinical Endocrinology \& Metabolism 100(2): 490-499.

2. Tomaschitz A, Ritz E, Pieske B, Rus-Machan J, Kienreich K, et al. (2014) Aldosterone and parathyroid hormone interactions as mediators of metabolic and cardiovascular disease. Metabolism 63(1): 20-31.

3. Mazzocchi G, Aragona F, Malendowicz LK, Nussdorfer GG (2001) PTH and PTH-related peptide enhance steroid secretion from human adrenocortical cells. American Journal of Physiology - Endocrinology and Metabolism 280(2): E209-E213.

4. Kovacs L, Góth MI, Szabolcs I, Dohán O, Ferencz A, et al. (1998) The effect of surgical treatment on secondary hyperaldosteronism and relative hyperinsulinemia in primary hyperparathyroidism. European Journal of Endocrinology 138(5): 543-547.

5. Brown JM, Williams JS, Luther JM, Garg R, Garza AE et al. (2014) Human Interventions to Characterize Novel Relationships Between the Renin-Angiotensin-Aldosterone System and Parathyroid Hormone. Hypertension 63(2): 273-280.

6. van Ballegooijen AJ, Reinders I, Visser M, Dekker JM, Nijpels G, et al. (2013) Serum Parathyroid Hormone in Relation to all-cause and Cardiovascular mortality: The Hoorn Study. J Clin Endocrinol Metab 98(4): E638-645.

7. Armanini $D$, Alessandra Andrisani, Guido Ambrosini, Gabriella Donà, Valentina Camozzi et al. (2016) Interrelationship Between Vitamin D Insufficiency, Calcium Homeostasis, Hyperaldosteronism and Autoimmunity. The Journal of Clinical Hypertension 18(7): 614-616.
8. de Borst MH, Vervloet MG, ter Wee PM, Navis G (2011) Cross Talk Between the Renin-Angiotensin-Aldosterone System and Vitamin D-FGF-23-klotho in Chronic Kidney Disease. J Am Soc Nephrol 22(9): 1603-1609.

9. Tomaschitz A, Pilz S, Ritz E, Grammer T, Drechsler C, et al (2010) Independent association between 1,25-dihydroxyvitamin D, 25-hydroxyvitamin D and the renin-angiotensin system: The Ludwigshafen Risk and Cardiovascular Health (LURIC) study.' Clinica Chinica Acta 411(17-18): 1354-1360.

10. Vaidya A, Forman JP, Hopkins PN, Seely EW, Williams JS, et al. (2011) 25-Hydroxyvitamin $D$ is associated with plasma renin activity and the pressor response to dietary sodium intake in Caucasians. Journal of the Renin-Angiotensin- Aldosterone System 12(3): 311-319.

11. Cheema T, Sherrod JN, Zhao W, Zhao T, Ahokas RA, et al. (2011) Mitochondriocentric pathway to cardiomyocyte necrosis in aldosteronism: cardioprotective responses to carvedilol and nebivolol. J Cardiovasc Pharmacol 58(1): 80-86.

12. van Ballegooijen AJ (2014) A potential role for parathyroid hormone in cardiovascular disease. OA Epidemiology 2(1): 8.

13. Brunaud L, Germain A, Zarnegar R, Rancier M, Alrasheedi S, et al. (2009) Serum aldosterone is correlated positively to parathyroid hormone (PTH) levels in patients with primary hyperparathyroidism. Surgery 146: 1035-1041.

14. Resnick LM, Laragh JH (1985) Calcium metabolism and parathyroid function in primary aldosteronism. Am J Med 78(3): 385-390.

15. Rossi E S, Perazzoli F, Casoli MC, Negro A, Dotti C, et al. (1995) Alterations of calcium metabolism and parathyroid function in primary aldosteronism, and their reversal by spironolactone or by surgical removal of adenomas. Am J Hypertension 8(9): 884-893.

16. Petramala L, Zinnamosca L, Settevendemmie A, Marinelli C, Nardi M, et al. (2014) Bone and Mineral Metabolism in Patients with Primary Aldosteronism. International Journal of Endocrinology 2014: 836529.

17. Maniero C, Fassina A, Guzzardo V, Lenzini L, Amadori G et al. (2011) Primary Hyperparathyroidism with Concurrent Primary Aldosteronism. Hypertension 58(3): 341-346.

18. Vaidya A, Brown JM, Williams JS (2015) The renin-angiotensinaldosterone system and calcium-regulatory hormones. Journal of Human Hypertension 29(9): 515-521.

19. Grant FD, Mandel SJ, Brown EM, Williams GH, Seely EW (1992) Interrelationship between the renin angiotensin-aldosterone and calcium homeostatic systems. J Clin Endocrinol Metab 75(4): 988-992.

20. Pilz S, Kienreich K, Drechsler C, Ritz E, Fahrleitner-Pammer A, et al. (2012) Hyperparathyroidism in patients with primary aldosteronism: cross-sectional and interventional data from the GECOH study. J Clin Endocrinol Metab 97(1): E75-E79.

21. Vaidya A, William JS (2012) The relationship between vitamin D and the renin-angiotensin system in the pathophysiology of hypertension, kidney disease, and diabetes. Metabolism 61(4): 450-458.

22. Andreas T, Eberhard R (2012) Aldosterone and PTH: a precarious couple for cardiovascular disease. Cardiovascular Research 94: 10-19.

23. Fischer SS, Kempe DS, Leibrock CB, Rexhepaj R, Siraskar B, et al. (2010) Hyperaldosteronism in Klotho-Deficient Mice. Am J Physiol Renal Physiol 299(5): F1171-F1177.

24. Tomascitz A, Ritz E, Pieske B, Fahrleitner Pammer A, Kienreich K et al. (2012) Aldosterone and parathyroid hormone: a precarious couple for cardiovascular disease. Cardiovascular Research 94(1): 10-19. 


Your next submission with Juniper Publishers
will reach you the below assets
- Quality Editorial service
- Swift Peer Review
- Reprints availability
- E-prints Service
- Manuscript Podcast for convenient understanding
- Global attainment for your research
- Manuscript accessibility in different formats
( Pdf, E-pub, Full Text, Audio)
- Unceasing customer service
Track the below URL for one-step submission
https://juniperpublishers.com/online-submission.php

